\title{
Evaluation of the Effect of Lactobacillus planetarium Probiotics Produced from Broad Bean Seed in Prevention of Helicobacter pylori in Stomach Tissue of C57BL/6 Mice
}

Amin Afsahi ${ }^{1}$, Hassan Mahmoudi ${ }^{2}$, Azizalah Ebrahimi ${ }^{1}, Z^{2}$ ahra Aeini ${ }^{1}$ and Davoud Esmaeili ${ }^{3 *}$

${ }^{1}$ Department of Pathobiology, Shahrekord University, Shahrekord, Iran

${ }^{2}$ Department of Microbiology, Hamadan University of Medical Sciences, Hamadan, Iran

${ }^{3}$ Department of Microbiology and Applied Microbiology Research Center, Systems Biology and Poisonings Institute, Baqiyatallah University of Medical Sciences, Tehran, Iran

\begin{abstract}
Background and aims: Helicobacter pylori is one of the most common human infections, which colonizes more than half of the world's population. This causes chronic stomach inflammation diseases without clinical syndromes, gastric and duodenal ulcer, and stomach cancer. Nowadays, the use of probiotics has received much consideration as one of the common therapeutic methods, which prevents bacterial colonization by creating a balance in the microbial gastrointestinal tract.
\end{abstract}

Methods: This experimental study was conducted on 30 rats in five groups from August 2016 to June 2017 in the Microbiology and Animal Laboratory of Shahrekord University. First, the rats were infected with $\mathrm{H}$. pylori bacteria. PCR method was used to confirm the presence of bacteria in the stomach to ensure that the rats were inoculated with $\mathrm{H}$. pylori. After inoculation, the infected rats were treated with probiotic product, and then gastric tissue of the infected group was evaluated by haematoxylin and eosin stain.

Results: The absence of Cag $A$ and Ure $C$ genes in fecal specimens of the group receiving probiotic products before and after $H$. pylori incubation showed a positive effect for this product on the prevention and treatment of $H$. pylori infection. Also, in stomach histology specimens, the effects of mild inflammation were observed in treated group with the probiotic product before and after $H$. pylori inoculation compared to the control group.

Conclusion: The results of this study showed that the addition of probiotic to a non-dairy product (broad bean extract) can be effective in preventing and treating $H$. pylori infection in the animal model.

Keywords: Helicobacter pylori; Probiotic; Broad bean; Haematoxylin; Gastrointestinal tract

\section{Introduction}

Helicobacter pylori is a gram-negative, motility, curved rod or spiralshaped bacterium. This has been isolated from the human stomach in all parts of the world. Colonization with $H$. pylori is associated with various diseases in the upper gastrointestinal tract such as gastritis, peptic ulcer, gastric cancer, and stomach lymphoma. It seems that the major reservoir of this bacterium is humans [1]. H. pylori is currently the only bacterial species that has been classified as a class I carcinogen by the International Agency for Research on Cancer (IARC). This bacterium is a cause of death worldwide. It has been reported that this germ-negative bacterium infects $50 \%$ of the world's population, and $80 \%$ of the population in developing countries [2,3]. Many people become infected with this bacterium until adulthood and it is difficult to prevent the infection even with the health observance. However, a vaccine has not been yet made in protecting human against $H$. Pylori, and the use of antibiotic is the only and current treatment method [4]. While $20 \%$ of the patients do not respond to the initial treatment. In this treatment method, poor medication adherence and drug resistance are the most common causes of the treatment failure. Nowadays, probiotics are commonly used as one of the best treatment methods to prevent microbial infection [4]. Probiotics are vital and specific microorganisms, which have beneficial effects on the host health by the use of its products in humans or animals such as regulating the balance of flora and reducing the side effects of antibiotics, especially diarrhea $[5,6]$. Lactobacillus is a gram-positive and fermentative bacterium and is commonly used as one of the most important probiotics. This bacterium in addition to the production of organic acids secretes several bacteriosens with antimicrobial properties. Most probiotics that have been studied until now or are available in the stores are safe and has so far not been reported any obvious side effects in the thousand consumers of these products [7-9]. Lactobacilli have the ability to survive and stay under acidic stomach conditions and are among the few bacteria that are separated from the acidic environment of the human stomach. In this regard, their inhibitory effects on $H$. pylori have received much attention [4]. According to previous studies on Lactobacillus strains, L. plantarum is an adaptive bacterium that can survive in different environments such as dairy products, meat and many fermentative vegetables. Other studies have also reported that $L$. plantarum by oral inoculation in five consecutive days can accelerate gastric ulcer healing in rats [9-11]. Broad bean (Vicia faba) is a family of legumes. It grows in different weather conditions of Europe, Africa and Asia, and it seems to have been one of the oldest beans used to prepare food. Flowers, flowering branches, fruits and seeds of broad bean are widely used for medical purposes. The plant contains essential nutrients for the body including phosphorus, potassium, vitamin $\mathrm{K}$ and

*Corresponding author: Davoud Esmaeili, Department of Microbiology and Applied Microbiology Research Center, Systems Biology and Poisonings Institute Baqiyatallah University of Medical Sciences, Tehran, Iran, Tel: +098-82483422; Fax: +098-21-82483422; E-mail: esm114@gmail.com

Received April 04, 2018; Accepted April 10, 2018; Published April 12, 2018

Citation: Afsahi A, Mahmoudi H, Ebrahimi A, Aeini Z, Esmaeili D (2018) Evaluation of the Effect of Lactobacillus planetarium Probiotics Produced from Broad Bean Seed in Prevention of Helicobacter pylori in Stomach Tissue of C57BL/6 Mice. J Cancer Sci Ther 10: 085-089. doi: 10.4172/1948-5956.1000524

Copyright: $\odot 2018$ Afsahi A, et al. This is an open-access article distributed under the terms of the Creative Commons Attribution License, which permits unrestricted use, distribution, and reproduction in any medium, provided the original author and source are credited. 
Citation: Afsahi A, Mahmoudi H, Ebrahimi A, Aeini Z, Esmaeili D (2018) Evaluation of the Effect of Lactobacillus planetarium Probiotics Produced from Broad Bean Seed in Prevention of Helicobacter pylori in Stomach Tissue of C57BL/6 Mice. J Cancer Sci Ther 10: 085-089. doi: 10.4172/1948-5956.1000524

iron. This plant is a good source of thiamine, which is vital for normal functioning of the nervous system and is also a rich source of fiber. Fiber helps the digestive system to break down food faster. Broad bean is low in calories and has no cholesterol. Its amino acid plays the role of the neurotransmitter in the brain $[12,13]$. The purpose of this study was to evaluate the effect of probiotic based on Vicia faba plant on the prevention and treatment of $H$. pylori infection in C57BL/6 mice. To our knowledge this is the first study to use probiotic in broad bean.

\section{Materials and Methods}

\section{Bacterial strain and growth condition}

The standard strain of $H$. pylori was provided from research center from the Gastrointestinal and Liver Diseases Research Center, Shahid Beheshti University of Medical Sciences, Tehran, Iran. The specimens were transferred to the microbiological laboratory, and then were cultured on Brucella agar-based media with $7.5 \%$ of sheep blood, $10 \%$ of the fetal bovine serum, and supplements containing antibiotics of amphotericin B $(2 \mathrm{mg} / \mathrm{L})$, vancomycin $(10 \mathrm{mg} / \mathrm{L})$, polymyxin $(0.25$ $\mathrm{mg} / \mathrm{L}$ ). After 3-4 days, the cultures obtained were placed at $37^{\circ} \mathrm{C}$ in anaerobic jar or gas pack $\mathrm{C}$, and then were identified using catalase and oxidase, gram staining, observation of gram-negative bacteria with specific morphology, and rapid urease test. After this process, the specimens were tested [14]. The standard strain of L. plantarum (ATCC8014) was provided in freeze-dried formulation from the collection of fungi and industrial and infectious bacteria in Iran and stored at $-80^{\circ} \mathrm{C}$ in a freezer.

\section{Animal experiments}

The present study was conducted in 2017 in the laboratory of microbiology. The required rats $(30$ male $\mathrm{C} 57 \mathrm{BL} / 6$ mice $)$ all were aged 6-8 weeks and weighed between 20-30 gr. All experiments were conducted based on the license number $(6572 / 9 / 35 / 16 / p)$ of the University's Medical Ethics Committee.

\section{Preparation and production of fermentation products}

Broad bean seeds were soaked in water for $12 \mathrm{~h}$, and then the seeds were crushed, and the resulting slurry was filtered and placed in a glass container. Next, the filtered solution was pasteurized at $70^{\circ} \mathrm{C}$ for $20 \mathrm{~min}$ in a heated bath. After cooling, $1 \%$ of the suspension (v/v) at concentration of $10^{6} \mathrm{CFU} / \mathrm{mL}$ of $L$. plantarum was added to the liquid and then incubated at $37^{\circ} \mathrm{C}$ for $48 \mathrm{~h}$ in the presence of $5 \%$ of $\mathrm{CO}_{2}[15]$.

\section{Infecting animals to $H$. pylori}

After transferring the rats to a laboratory for keeping animals and adapting the animal to the new environment (Three days after transfer), the first fecal specimen (before the experiment) was taken from all studied groups. To increase the chance of $H$. pylori colonization in the stomach of the fats, their feeding was discontinued 24 hours before the inoculation. A suspension of pure culture of $H$. pylori in physiological serum was prepared and its opacity was adjusted according to the standard McFarland half-size (equivalent to $1.5 \times 10^{8}$ cells per $\mathrm{mL}$ ). Then, volumes of $1 \mathrm{~mL}$ of the suspension were poured directly into the stomach of the rats in groups of 1-4 by using a polyethylene tube. This procedure was repeated three times a week and at intervals of every two days. Totally, 3 times this procedure was repeated, and after the last inoculation, the animals fed normally.

\section{Inoculation of probiotic product to animals}

In group 1 rats, $100 \mu \mathrm{L}$ of the extract was inoculated daily (gavage). In group 2 rats, two weeks before $H$. pylori inoculation, the extract was incubated in the stomach of the rats. In group 3 rats, two weeks after $H$. pylori inoculation, the most common used antibiotics for treating $H$. pylori (including a combination of metronidazole, erythromycin and bismuth) was used for 2 weeks.

\section{Stool sampling}

Fecal samples were ordinarily collected from the rats before and on weeks of $3,5,7$, and 12 after inoculation, and then the collected samples were stored at $20^{\circ} \mathrm{C}$ in a freezer.

\section{DNA extraction and replication by PCR method}

In this study, to extract DNA, the DNA extraction kit (Gene all, South Korea) was used. Then, the proliferation of the $c a g A$ and the ure $C$ genes in relation to $H$. pylori were investigated using the specific primers (Table 1). The program time and temperature for PCR in 35 cycles were as follows: $3 \mathrm{~min}$ of the initial denaturation at $95^{\circ} \mathrm{C}, 45 \mathrm{sec}$ of the second denaturation at $93^{\circ} \mathrm{C}, 60 \mathrm{sec}$ of annealing at $55^{\circ} \mathrm{C}, 60 \mathrm{sec}$ of extension at $72^{\circ} \mathrm{C}$, and the final stage of expansion was conducted at $72^{\circ} \mathrm{C}$ for $5 \mathrm{~min}$. Then, PCR product was observed on agarose gel $(1.5 \%)$ by using electrophoresis method [16,17].

\section{Histological examination of stomach tissue}

For histological examination of the stomach samples, an animal was randomly selected from each group on week of 12 after inoculation. After killing animals, their stomach was removed with chloroform and it was cut off from the big bend area. After removing the contents of the stomach, the total stomach tissue was placed in $10 \%$ formalin. After transferring the specimens to the histological laboratory, the stomachs were placed in paraffin (Figure 1). The stomach tissue was divided into $5 \mu \mathrm{m}$ tissue slices for histological examination. The tissue slices were stained with Hematoxylin and Eosin stains and examined using optical microscopy.

\section{Results}

\section{Identification of bacteria}

The electrophoresis of PCR products showed a fragment of the 400-

\begin{tabular}{|c|c|}
\hline Group & Characteristics of the studied group \\
\hline 1 & $\begin{array}{c}\text { Two weeks before } H \text {. pylori inoculation, they were daily fed the product } \\
\text { via gavage and diet. }\end{array}$ \\
\hline 2 & $\begin{array}{l}\text { Two weeks after } H . \text { pylori inoculation, they were daily fed the product } \\
\text { via diet and gavage. }\end{array}$ \\
\hline 3 & $\begin{array}{l}\text { They were treated with common drugs used to treat } H \text {. pylori for three } \\
\text { weeks }\end{array}$ \\
\hline 4 & Control group with $H$. pylori inoculation and without treatment \\
\hline 5 & Control group without $H$. pylori inoculation and without treatment \\
\hline
\end{tabular}

Table 1: Characteristics of studied groups.

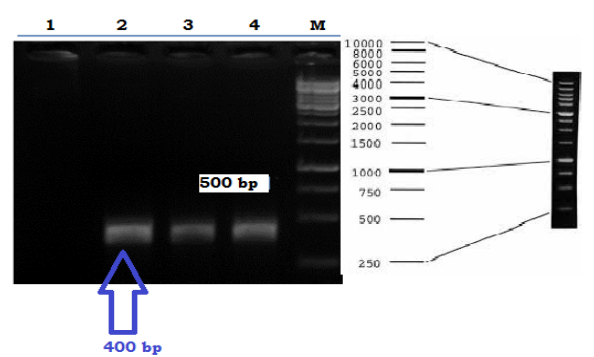

Figure 1: PCR results of CagA genes: well 1: Negative control samples, well 2: Positive control samples, wells 3 and 4: Positive samples in terms of the presence of the cagA gene, well M: Marker is $1 \mathrm{~kb}$. 
Citation: Afsahi A, Mahmoudi H, Ebrahimi A, Aeini Z, Esmaeili D (2018) Evaluation of the Effect of Lactobacillus planetarium Probiotics Produced from Broad Bean Seed in Prevention of Helicobacter pylori in Stomach Tissue of C57BL/6 Mice. J Cancer Sci Ther 10: 085-089. doi: 10.4172/1948-5956.1000524

base pair of $\operatorname{cagA}$ gene and 294 base pair of the $u r e C$ gene associated with $H$. pylori (Figures 2 and 3 ).

\section{Study of the presence of $H$. pylori in animal stool using PCR method}

The lack of propagation of the specific portion of 400 and 294 base pairs in the first stool sample of animals (before H. pylori inoculation) showed that none of the animals were naturally infected with the bacterium. The second fecal specimen was taken three weeks after $H$. pylori inoculation. This is due to the fact that before three weeks, the positive PCR response does not indicate the definitive infection with H. pylori, and it may be attributed to the transient bacteria and without deployment of the bacteria in the stomach. The result of the PCR was positive for groups 4 (control group with $H$. pylori inoculation), and the PCR results of other groups were negative. Moreover, the proliferation of $\mathrm{CagA}$ and UreC gene from animal stools in groups $1,2,3$ and 5 at $3,5,7$ and 12 weeks after inoculation was also negative, while it was positive in group 4 was positive (Table 2).

\section{Histopathological examination of the stomach tissue}

The strained gastric slices of 1 animal stomach from each group at week 12 after $H$. pylori inoculation were studied in term of the degree of inflammation using an optical microscopy. The severity of inflammation for each histology sample was graded from 1 to 4 at

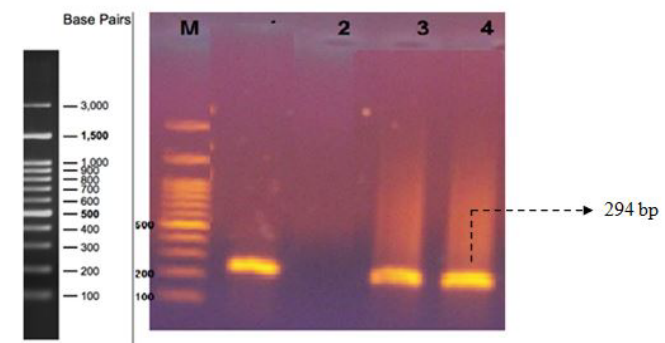

Figure 2: Results of PCR of Ure $C$ genes: well M: Marker is $100 \mathrm{bp}$, well 1 : Positive control samples, well 2: Negative control samples, wells 3 to 4: Positive samples in terms of the presence of ure $C$ gene.

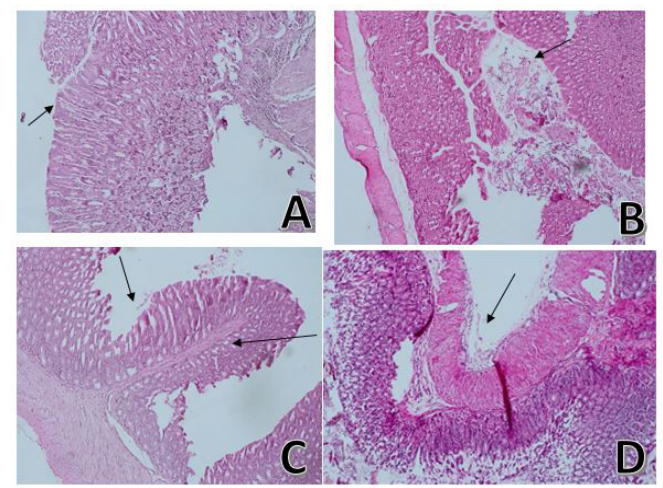

Figure 3: Gastric pathology examples of intervention groups: Control group (A): Gastric tissue without pathological changes, Group 1 (B): finding a small number of leukocytes dispersed at depth of mucous, inflammation and mild degradation of mucous, Group 2 (C): finding the average number of leukocytes in depth or middle of the mucosa, and sometimes neutrophils in the glands and mild inflammation in the mucosa and sub-mucosa, group 3 (D): observation of a mild mucosal degeneration, group $4(E)$ : observation of a dense leukocyte infiltration in depth or middle of the mucosa, and the degradation of the mucosa in the anthrom tissue.

\begin{tabular}{|c|c|c|c|c|c|}
\hline \multicolumn{2}{|c|}{$\begin{array}{l}\text { Primer } \\
\text { Name }\end{array}$} & 5' to 3' Sequence prime & \begin{tabular}{|} 
Product \\
size \\
(bp)
\end{tabular} & $\begin{array}{c}\text { Annealing } \\
\text { temperature } \\
\left({ }^{\circ} \mathrm{C}\right)\end{array}$ & Reference \\
\hline \multirow{2}{*}{$\operatorname{cagA}$} & $\mathrm{F}$ & AATACACCAACGCCTCCAAG & \multirow{2}{*}{$400 \mathrm{bp}$} & \multirow{2}{*}{55} & \multirow{2}{*}{ Izadi et al. } \\
\hline & $\mathrm{R}$ & TTGTTGCCGCTTTTGCTCTC & & & \\
\hline \multirow{2}{*}{ ureC } & $\mathrm{F}$ & $\begin{array}{c}\text { AAGCTTTTAGGGGTGT- } \\
\text { TAGGGGTTT }\end{array}$ & \multirow{2}{*}{$294 b p$} & \multirow{2}{*}{55} & \multirow{2}{*}{$\begin{array}{c}\text { de } \mathrm{Ne}- \\
\text { greiros } \\
\text { Bessa et al. }\end{array}$} \\
\hline & $\mathrm{R}$ & $\begin{array}{c}\text { AAGCTTACTTTCTAACAC- } \\
\text { TAACGC }\end{array}$ & & & \\
\hline
\end{tabular}

Table 2: The primer used in this study.

\begin{tabular}{|c|c|c|c|}
\hline Group & Type of tests & $\begin{array}{c}\text { Inflammation } \\
\text { intensity }\end{array}$ & Pathological changes \\
\hline 1 & $\begin{array}{c}\text { Intaking probiotic } \\
\text { products two } \\
\text { weeks before } \\
\text { inoculation }\end{array}$ & 1 & $\begin{array}{c}\text { A small number of leukocytes } \\
\text { dispersed in depth of mucus and } \\
\text { inflammation and mild degradation } \\
\text { of mucus }\end{array}$ \\
\hline 3 & $\begin{array}{c}\text { Intaking probiotic } \\
\text { products two } \\
\text { weeks after } \\
\text { inoculation } \\
\text { Intaking the } \\
\text { usual treatment } \\
2 \text { weeks after } \\
\text { inoculation }\end{array}$ & 2 & $\begin{array}{c}\text { Average number of leukocytes in } \\
\text { depth or middle of the mucus and } \\
\text { sometimes neutrophils in the glands } \\
\text { and mild inflammation in the mucosa } \\
\text { and under the mucosa }\end{array}$ \\
\hline 4 & $\begin{array}{c}\text { Control (bacterial } \\
\text { inoculation) }\end{array}$ & 3 & $\begin{array}{r}\text { Mild mucus degradation } \\
\text { or middle of the mucosa and mild } \\
\text { degradation of the mucosa in the } \\
\text { anthrom tissue }\end{array}$ \\
\hline 5 & Control & 0 & $\begin{array}{r}\text { Without change } \\
\hline\end{array}$
\end{tabular}

Table 3: Scale of gastric inflammation of the studied rats in intervention groups.

a relatively high-quality scale with $40 \mathrm{x}$ microscopic magnification (Figure 3). Table 3 shows the changes in the stomach tissue.

\section{Discussion}

This study aimed to investigate the effect of probiotic product produced from broad bean seed fermentation on the prevention and treatment of $H$. pylori infection in C57BL/6 mice and compare its effect with the standard treatment method. In the present study, the PCR results of all specimens were negative before $H$. pylori inoculation and this finding showed no naturally infection with this bacterium. The positive result of the samples after $H$. pylori inoculation in group 4 (control + bacterium inoculation) confirmed the successful bacterial colonization in the animal stomach. Moreover, in histological examination of stomach sample, the mild degradation was apparent in the anthrome tissue. The negative result of samples in group 5 (controls without inoculation) also showed that there was no environmental contamination and possible error. There were no inflammation and degradation effects in histological examination of stomach samples.

The result of the PCR test in group 1 (intake of daily probiotic product, 2 weeks before inoculation) showed a negative presence of Cag A and Ure C genes, and there was also a very slight degree of inflammation (grade 1) in their stomach tissue samples. The results of the PCR test in group 2 (intake of daily probiotic product, 2 weeks after inoculation) and group 3 (intake of common drugs, 2 weeks after inoculation) were also negative, and in histological examination of specimen in group 2 and 3 showed a light (grade 2) and mild (grade 1) inflammation, respectively. Chen study on the anti-hiclubacter effect of 38 strains of lactobacillus showed that the L. plantarum strain had the most anti-H. Pylori effect and significantly reduced the activity of 
Citation: Afsahi A, Mahmoudi H, Ebrahimi A, Aeini Z, Esmaeili D (2018) Evaluation of the Effect of Lactobacillus planetarium Probiotics Produced from Broad Bean Seed in Prevention of Helicobacter pylori in Stomach Tissue of C57BL/6 Mice. J Cancer Sci Ther 10: 085-089. doi: 10.4172/1948-5956.1000524

urease urinary vectors [18]. Xiaohua study showed an inhibition effect of two strains of L. gasseri and L. plantarum on H. pylori growth under laboratory conditions [19]. El-Adawi et al. reported that L. bulgaricus, L. acidophilus and L. plantarum had the most anti-helicobacterial effect and prevented adhesion and invasion of the bacteria and reduced the level of TNF- $\alpha$ by $62.13 \%$ [20].

In the present study, L. plantarum strain was used to prepare a fermented probiotic product. Our results also confirmed the antibacterial activity of this strain, which is consistent with the findings of the previous studies. Chompoonut et al. showed that daily inoculation of $L$. plantarum inhibited the growth of $H$. pylori for a week, reduced inflammation, and significantly improved the gastric tissue of the rat, and these effects were also dependent on the inoculated dosage, which this finding are consistent our results [21]. Rokka study showed the anti-helicobacter effect of various strains of L. plantarum under laboratory conditions. They introduced and proposed the production of a fermentation product containing lactobacillus as a potential and strong tool for the treatment of $H$. pylori infection [22]. Our results are consistent with the findings of Rokka study, and our study confirmed the hypothesis proposed in this research. Mingfang Pan et al. study indicated that the pre-treatment with L. plantarum prevented the increase of inflammatory cytokines such as IFN- $\gamma$ in $H$. pylori infection and played an important role in preventing inflammation of the gastric mucosal tissue. Moreover, they introduced oral treatment with probiotic products of $L$. plantarum as an alternative and suitable treatment method for the prevention of $H$. pylori infection [23].

The results of this study also indicated that two weeks before inoculation the intake of probiotic products can prevent $H$. pylori infection. The Thiraworawong study showed that $L$. plantarum reduced the inflammation caused by $H$. pylori infection in the stomach of the studied rats and may result in TNF- $\alpha$ suppression and can be used as an adjunctive therapy in the treatment of this infection [24]. This is in line with the results of our study. In the present study, the extract of broad bean plant was first used to prepare a probiotic product. The results of this study showed that the probiotic produced from broad bean plant can be successfully used for the prevention and treatment of $H$. pylori infection in the animal model of C57BL/6 rat $[25,26]$. Therefore, with regard to the growing interest of people around the world for the use of beans and legumes and the consumption of foods containing them, the bean extract (as one of the herbaceous plants) to produce a cheap, available, low-calorie and cholesterol-free probiotic product.

The plant contains essential nutrients such as phosphorus, potassium, vitamin $\mathrm{K}$ and iron, and is an excellent source of thiamine, which is essential for maintaining the normal functioning of the nervous system. Vitamin A is essential for normal vision, as well as proper bone growth and healthy skin. High levels of potassium in the bean helps the bodies maintain a normal blood pressure and regulate heart functions. The phosphorus in this plant is essential in the formation of bones and teeth and helps the body to use vitamins. Its high fiber content helps the digestive tract to digest food faster, and its amino acid plays the role of the neurotransmitter in the brain [25-27]. Despite the good nutritional value and availability of this plant, it seems that it plant can be successfully used in the food and pharmaceutical industries.

However, Rossana Coda et al. investigated the fermentation effect of L. plantarm (as a starter) on broad bean flour to reduce nutrients such as, vicin, convizion, and phytic acid as well as increase the quality of the food. Their results showed that fermentation can be effectively used for reducing and eliminating anti-nutritional compounds, increasing digestibility of proteins, and improving the quality of the broad bean. Therefore, with regard to the results from previous studies and our findings, it seems that the production of probiotic products based on broad bead plant in addition to helping prevent and treat $H$. pylori infection. As previously mentioned, $H$. pylori is one of the most common human infections that accounts for approximately more than half of the world's population. It causes chronic stomach ulcer disease, gastric and duodenal ulcers, and gastric cancer $[28,29]$. Due to high levels of infection, risk of ulcers and gastric cancer unsuccessfulness of as a treatment method the complete removal of infection from the body in all patients, and risk of recurrence in treated patients, especially growing drug resistance in this bacterium. The results of this study can be helpful in eradicating and reducing the side effects of treatment for this infection.

\section{Conclusion}

In this study, the addition of probiotic to non-dairy products (broad bean plant extract) and its successful testing in the prevention and treatment of $H$. pylori infection in the animal model can be considered as a novelty of this study compared to previous related research. To our knowledge this is the first study to use probiotic in broad bean.

\section{Suggestions}

Considering the positive results of this study in the prevention and treatment of $H$. pylori infection, it is suggested that future studies focus on the survival time of different probiotics in the broad bean plant extract and producing a non-dairy probiotic product with low cost and higher nutritional value for treating and preventing $H$. pylori infection.

\section{References}

1. Blaser M (2005) Helicobacter pylori and other gastric Helicobacter species Mandell, Douglas, and Bennett's principles and practice of infectious diseases. (5th edn) New York: Elsevier/Churchill Livingstone 2557-2567.

2. Blaser MJ (1990) Helicobacter pylori and the pathogenesis of gastroduodenal inflammation. J Infect Dis 161: 626-633.

3. Megraud F (2004) H pylori antibiotic resistance: prevalence, importance, and advances in testing. Gut 53: 1374-1384.

4. Baltrus DA, Blaser MJ, Guillemin K (2009) Helicobacter pylori genome plasticity. Genome Dyn 6: 75-90.

5. Campieri M, Gionchetti $P$ (2001) Bacteria as the cause of ulcerative colitis. Gut 48: $132-135$

6. Stanton C, Gardiner G, Meehan H, Collins K, Fitzgerald G, et al. (2001) Market potential for probiotics. Am J Clin Nutr 73: 476s-483s.

7. Saavedra JM (2001) Clinical applications of probiotic agents. Am J Clin Nut 73: $1147 \mathrm{~S}-1151 \mathrm{~S}$

8. Salminen S, Bouley C, Boutron-Ruault MC, Cummings $\mathrm{JH}$, Franck $\mathrm{A}$, et al. (1998) Functional food science and gastrointestinal physiology and function. Br J Nutr 80: S147-S171.

9. Guarner F, Schaafsma GJ (1998) Probiotics. Int J Food Microbiol 39: 237-238

10. Isolauri E, Juntunen M, Rautanen T, Sillanaukee $P$, Koivula T (1991) A human Lactobacillus strain (Lactobacillus casei sp strain GG) promotes recovery from acute diarrhea in children. Pediatrics 88: 90-97.

11. Orrhage K, Brismar B, Nord CE (1994) Effect of supplements with Bifidobacterium longum and Lactobacillus acidophilus on the intestinal microbiota during administration of clindamycin. Microbial ecology in health and disease $7:$ 17-25.

12. Brassart D, Schiffrin E, Rochat F, Offord EA, Mace C, et al. (1998) The future of functional foods: scientific basis and future requirements. LebensmittelTechnologie 258-266.

13. Moosavi SG, Seghatoleslami MJ, Delarami MR (2014) Effect of sowing date and plant density on yield and yield components of lentil (Lens culinaris CV. Sistan). Ann Res Rev Biol 4: 296-305. 
Citation: Afsahi A, Mahmoudi H, Ebrahimi A, Aeini Z, Esmaeili D (2018) Evaluation of the Effect of Lactobacillus planetarium Probiotics Produced from Broad Bean Seed in Prevention of Helicobacter pylori in Stomach Tissue of C57BL/6 Mice. J Cancer Sci Ther 10: 085-089. doi: 10.4172/1948-5956.1000524

14. Talebi Bezmin Abadi A, Mobarez AM, Taghvaei T, Wolfram L (2010) Antibiotic resistance of Helicobacter pylori in Mazandaran, North of Iran. Helicobacter 15: 505-509.

15. Beerens H, Romond C, Neut C (1980) Influence of breast-feeding on the bifid flora of the newborn intestine. Am J Clin Nutr 33: 2434-2439.

16. de Negreiros Bessa PP, Barbosa FC, Santos do Carmo AP, Furtado GB, Barroso FC, et al. (2014) Presence of the genes cagA, cagE, virB11 and allelic variation of vacA of Helicobacter pylori are associated with the activity of gastritis. Open Journal of Gastroenterology 4: 347.

17. Izadi F, Ahmadi A, Ghourchian S, Daneshi A, Memari F, et al. (2012) Detection of Helicobacter pylori in benign laryngeal lesions by polymerase chain reaction: a cross sectional study. Infect Agent Cancer 7: 10.

18. Chen X, Tian F, Liu X, Zhao J, Zhang HP, et al. (2010) In vitro screening of Lactobacilli with antagonistic activity against Helicobacter pylori from traditionally fermented foods. J Dairy Sci 93: 5627-5634.

19. Chen X, Liu XM, Tian F, Zhang Q, Zhang HP, et al. (2012) Antagonistic activities of lactobacilli against Helicobacter pylori growth and infection in human gastric epithelial cells. J Food Sci 77: 9-14.

20. El-Adawi H, El-Sheekh M, Khalil M, El-Deeb N, Hussein M (2013) Lactic acid bacterial extracts as anti-Helicobacter pylori: a molecular approach. Ir J Med Sci 182: 439-452.

21. Sunanliganon C, Thong-Ngam D, Tumwasorn S, Klaikeaw N (2012) Lactobacillus plantarum B7 inhibits Helicobacter pylori growth and attenuates gastric inflammation. World J Gastroenterol 18: 2472-2480.
22. Rokka S, Pihlanto A, Korhonen $\mathrm{H}$, Joutsjoki V (2006) In vitro growth inhibition of Helicobacter pylori by lactobacilli belonging to the Lactobacillus plantarum group. Lett Appl Microbiol 43: 508-513.

23. Pan M, Wan C, Xie Q, Huang R, Tao X, et al. (2016) Changes in gastric microbiota induced by Helicobacter pylori infection and preventive effects of Lactobacillus plantarum ZDY 2013 against such infection. J Dairy Sci 99: 970-981.

24. Thiraworawong T, Spinler JK, Werawatganon D, Klaikeaw N, Venable SF, et al. (2014) Anti-inflammatory properties of gastric-derived Lactobacillus plantarum XB7 in the context of Helicobacter pylori Infection. Helicobacter 19: 144-155.

25. Boudjou S, Zaidi F, Hosseinian F, Oomah BD (2014) Effects of faba bean (Vicia faba L.) flour on viability of probiotic bacteria during kefir storage. J Food Sc Res 3: 13

26. Coda R, Melama L, Rizzello CG, Curiel JA, Sibakov J, et al. (2015) Effect of air classification and fermentation by Lactobacillus plantarum VTT E-133328 on faba bean (Vicia faba L.) flour nutritional properties. Int J Food Microbio 193: 34-42.

27. Gullón P, Gullón B, Tavaria F, Vasconcelos M, Gomes AM (2015) In vitro fermentation of lupin seeds (Lupinus albus) and broad beans (Vicia faba) dynamic modulation of the intestinal microbiota and metabolomic output. Food Funct 6: 3316-3322.

28. Attia EA, Abdel Fattah NS, Abdella HM (2010) Upper gastrointestinal findings and detection of Helicobacter pylori in patients with oral lichen planus. Clin Exp Dermatol 35: 355-360.

29. Fuentes-Pananá E, Camorlinga-Ponce M, Maldonado-Bernal C (2009) Infection, inflammation and gastric cancer. Salud publica de Mexico 51: 427-433. 